\title{
One-Stage Nipple and Breast Reconstruction Following Areola-Sparing Mastectomy
}

\author{
Hye Ri Kim, Jin Soo Lim, Sue Min Kim, Sung No Jung, Gyeol Yoo, Eun Young Rha \\ Department of Plastic Surgery, The Catholic University of Korea College of Medicine, Seoul, Korea
}

Background Skin-sparing mastectomy with immediate breast reconstruction is increasingly becoming a proven surgical option for early-stage breast cancer patients. Areola-sparing mastectomy (ASM) has also recently become a popular procedure. The purpose of this article is to investigate the reconstructive and aesthetic issues experienced with one-stage nipple and breast reconstruction using ASM.

Methods Among the patients who underwent mastectomy between March 2008 and March 2010, 5 women with a low probability of nipple-areolar complex malignant involvement underwent ASM and immediate breast reconstruction with simultaneous nipple reconstruction using the modified $\mathrm{C}-\mathrm{V}$ flap. The cosmetic outcomes of this series were reviewed by plastic surgeons and patient self-assessment and satisfaction were assessed via telephone interview. Results During the average 11-month follow-up period, there were no cases of cancer recurrence, the aesthetic outcomes were graded as excellent to very good, and all of the patients were satisfied. Two patients developed a gutter-like depression around the reconstructed nipple, and one patient developed skin erosion in a small area of the areola, which healed with conservative dressing. The other complications, such as necrosis of the skin flap or areola, seroma, hematoma, or fat necrosis did not occur.

Conclusions Since one-stage nipple and breast reconstruction following ASM is an oncologically safe, cost-effective, and aesthetically satisfactory procedure, it is a good surgical option for early breast cancer patients.

Keywords Breast / Mammaplasty / Nipples / Mastectomy
Correspondence: Gyeol Yoo Department of Plastic Surgery, The Catholic University of Korea College of Medicine, 10 yuksam-ro, Yeongdeungpo-gu, Seoul 150-713, Korea

Tel: +82-2-3779-1198

Fax: $+82-2-780-9167$

E-mail:psyg@catholic.ac.kr

Received: 27 Mar 2013 • Revised: 25 Jun 2013 • Accepted: 4 Jul 2013

pISSN: 2234-6163 • elSSN: 2234-6171 • http://dx.doi.org/10.5999/aps.2013.40.5.553 • Arch Plast Surg 2013;40:553-558

No potential conflict of interest relevant to this article was reported.

\section{INTRODUCTION}

The quality of life of breast cancer patients who undergo mastectomy can be severely impaired, not only because of psychological trauma, but also because of aesthetic problems. Breast reconstruction after mastectomy is extremely important for improving patients' quality of life, and immediate breast reconstruction has both aesthetic and psychological advantages over conventional delayed reconstruction [1]. The cosmetic results of mastectomy and immediate reconstruction can be greatly improved by the resection of less skin in skin-sparing mastectomy [2-4]. Recently, a majority of the women who were found to have breast cancer were diagnosed in the early stages, thereby making breast conservation treatment feasible. Fortunately, most of these women no longer need to undergo surgery, which has serious consequences - both physical and psychological. However, for those who do need to undergo surgery, an increasingly popular option is skin-sparing mastectomy (SSM) with immedi-

Copyright $(\odot 2013$ The Korean Society of Plastic and Reconstructive Surgeons

This is an Open Access article distributed under the terms of the Creative Commons Attribution Non-Commercial License (http://creativecommons.org/

licenses/by-nc/3.0/) which permits unrestricted non-commercial use, distribution, and reproduction in any medium, provided the original work is properly cited.

www.e-aps.org 
ate breast reconstruction. For a more natural breast reconstruction, SSM is preferred to conventional mastectomy when it is guaranteed to be oncologically safe. The advantages of this method include improved cosmetic results without an increased risk of cancer recurrence or other complications. Because the nippleareolar complex is excised in SSM, nipple reconstruction is necessary. Recently, a new concept of areola-sparing mastectomy (ASM) has emerged $[5,6]$.

Reconstruction of the nipple-areolar complex has also been performed as a final procedure of breast reconstruction when SSM has been performed because of any potential asymmetry resulting from the loss of bulk and unpredictable ptosis of the reconstructed breast [7]. However, the authors performed immediate nipple reconstruction with immediate breast reconstruction in the case of ASM because the nipple would be less displaced after the remodeling period. The purpose of this study is to review our early experience of one-stage nipple and breast reconstruction following ASM, with a special focus on aesthetic outcomes and reconstructive issues.

\section{METHODS}

Between March 2008 and March 2010, 5 women underwent ASM and immediate breast reconstruction with simultaneous nipple reconstruction. In all of the cases, the cancer was less than $4 \mathrm{~cm}$ in size ( 1 case of ductal carcinoma in situ [DCIS], 4 cases of invasive lobular carcinoma) and non-multicentric. The breasts were reconstructed with the free transverse rectus abdominis myocutaneous flap (free TRAM flap) or latissimus dorsi muscle flap (LD flap) and a silicone breast implant, and the nipples were simultaneously reconstructed (Table 1).

The initial incision was made by a general surgeon, circumfer-

Table 1. Patient demographics, histopathologic findings, and details of reconstruction

\begin{tabular}{|lcccc|}
\hline No. & $\begin{array}{c}\text { Sex/Age } \\
\text { (yr) }\end{array}$ & $\begin{array}{c}\text { Definitive } \\
\text { Histology }\end{array}$ & $\begin{array}{c}\text { Cancer } \\
\text { size }(\mathbf{c m})\end{array}$ & $\begin{array}{c}\text { Reconstruction } \\
\text { method }\end{array}$ \\
\hline 1 & F/29 & $\begin{array}{c}\text { Invasive lobular } \\
\text { carcinoma }\end{array}$ & $3.9 \times 3.6$ & $\begin{array}{c}\text { Free TRAM flap and } \\
\text { modified C-V flap }\end{array}$ \\
2 & F/33 & $\begin{array}{c}\text { Invasive lobular } \\
\text { carcinoma }\end{array}$ & $1.8 \times 1.5$ & $\begin{array}{c}\text { LD flap and implant, } \\
\text { and modified C-V } \\
\text { flap }\end{array}$ \\
4 & F/45 & $\begin{array}{c}\text { Ductal carcinoma } \\
\text { in situ }\end{array}$ & $1.5 \times 0.5$ & $\begin{array}{c}\text { Free TRAM flap and } \\
\text { modified C-V flap }\end{array}$ \\
5 & F/33 & $\begin{array}{c}\text { Invasive lobular } \\
\text { carcinoma } \\
\text { Invasive lobular } \\
\text { carcinoma }\end{array}$ & $2.3 \times 1.3$ & $\begin{array}{c}\text { Free TRAM flap and } \\
\text { modified C-V flap }\end{array}$ \\
\hline $\begin{array}{l}\text { TRAM flap, transverse rectus abdominis musculocutaneous flap; LD flap, latissimus } \\
\text { dorsi flap. }\end{array}$ & F/36 & $\begin{array}{c}\text { Free TRAM flap and } \\
\text { modified C-V flap }\end{array}$ \\
\hline
\end{tabular}

entially along the base of the nipple with a linear lateral extension on one side or both sides (Fig. 1A). The nipple was resected along with the breast parenchyma, and the skin envelope including the areola was preserved. A frozen section biopsy was performed using the tissue from the undersurface of the areolar flap to confirm that the tissue did not show microinvasion. Resection of the entire breast parenchyma and axillary lymph node dissection were performed subsequently (Fig. 1B). After the completion of ASM by the general surgeon, trimming of the elevated TRAM or LD flap was performed considering the overall breast shape and volume while maintaining a sufficient skin island for nipple reconstruction. After setting the TRAM or LD flap in the mastectomy site, the nipple defect was marked on the skin paddle of the TRAM or LD flap. We designed a modified C-V flap on the skin island of the reconstructed flap and performed deepithelization of the remnant skin paddle (Fig. 1C, D). After the nipple was reconstructed using the modified C-V flap [8], the reconstructed nipple was inset into the remaining areolar skin (Fig. 2). Two to six months later, tattooing of the nipples was performed.

The reconstructive and cosmetic results were evaluated by two plastic surgeons using the evaluation method proposed by Salgarello et al. [9]. This assessment was based on 8 items (volume, contour, inframammary crease, breast symmetry, nippleareola complex aesthetic outcome, skin flap and skin flap edge, scars, and overall result) with three Likert subscales through clinical examinations and by reviewing clinical photos of the breasts. Furthermore, patient self-assessment and satisfaction were assessed via telephone interview by applying the BREASTQ Reconstruction Module's 15-item scale, "Satisfaction with breasts" $[10,11]$. The BREAST-Q is a patient-reported outcome measure that addresses issues such as the shape and size of the reconstructed breast, comfort, softness, symmetry, and patient's feeling of "normalcy". We gathered patient data on these issues and classified the overall results as very dissatisfied, somewhat dissatisfied, somewhat satisfied, and very satisfied.

\section{RESULTS}

The average follow-up time was 11 months (range, 6 to 18 months). There were no cases of cancer recurrence, and the reconstructive outcomes were graded as excellent in 3 patients and as very good in two patients (Figs. 3, 4). All of the patients were satisfied with the aesthetic outcomes and especially with having the breast reconstructions completed in a single stage.

Two patients developed a gutter-like depression around the reconstructed nipple (Fig. 3). One patient developed skin erosion in a small area of the areola that healed after conservative 


\section{Fig. 1. Diagram of one-stage nipple and breast reconstruction}

(A) Incision line for areolar-sparing mastectomy. (B) Diagram after areolar-sparing mastectomy. (C) Design for modified C-V flap (thin linear arrow) and the area of deepithelization (thick black arrow) of the remnant skin paddle of the flap after insetting of the latissimus dorsi muscle or transverse rectus abdominis myocutaneous flap. The white thick arrow shows the remaining areola before closing the wound. (D) Vertical cross section. The arrows indicate the same as that in Fig. $1 \mathrm{C}$.

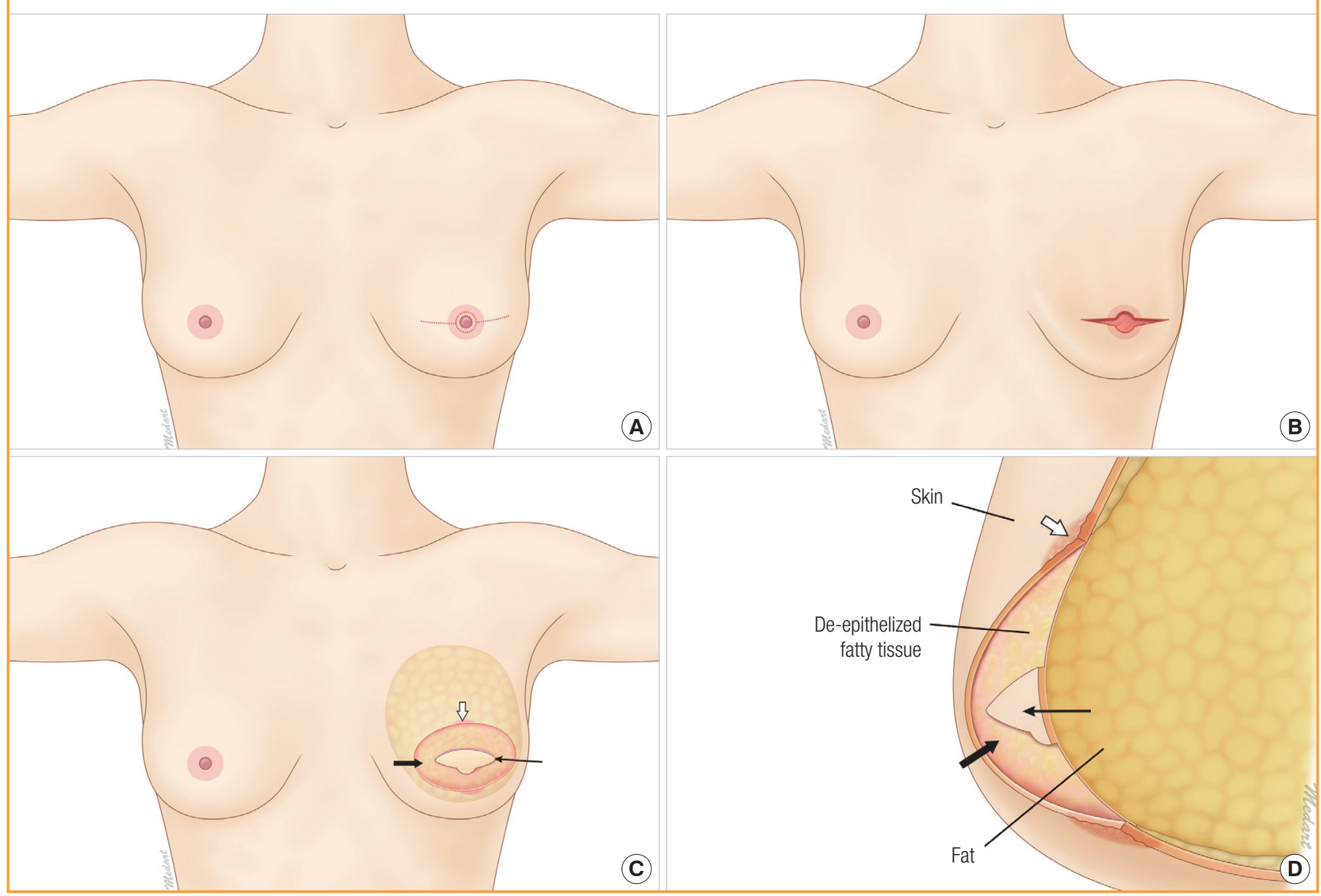

Fig. 2. Photograph of one-stage nipple and breast reconstruction

A 32-year-old female underwent immediate TRAM flap breast reconstruction after ASM of the left breast through 2-cm-long incisions on both the sides of the areola. The nipple was simultaneously reconstructed using the modified $\mathrm{C}-\mathrm{V}$ flap from the skin paddle of a TRAM flap. TRAM, transverse rectus abdominis myocutaneous; ASM, areola-sparing mastectomy.

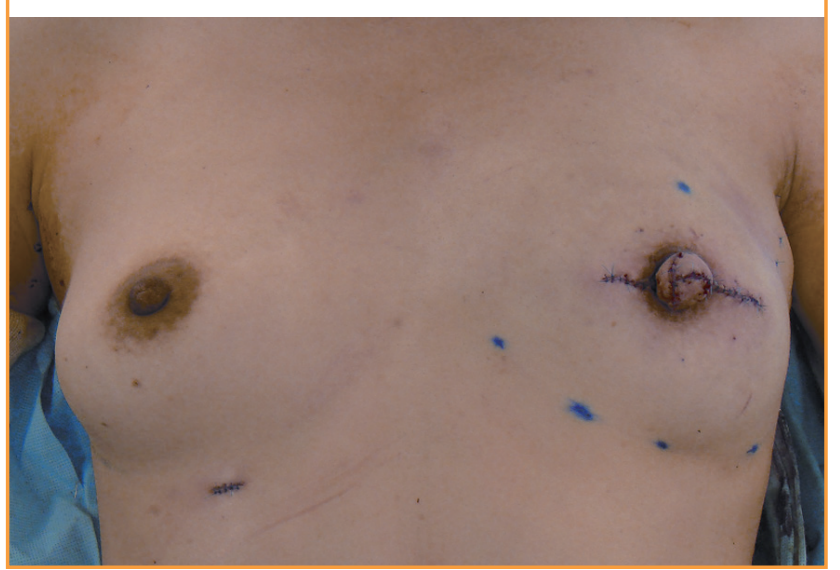

treatment. In this case, hypopigmentation developed in this area after complete healing, and additional tattooing was performed concurrently with nipple tattooing. Other complications, such as necrosis of the skin flap or areola, seroma, hematoma, or fat necrosis did not occur.

\section{Case 1}

A 29-year-old female visited with invasive lobular carcinoma measuring $3.9 \mathrm{~cm} \times 3.6 \mathrm{~cm}$ in size in the upper outer quadrant of the right breast without nipple involvement. The tumor mass was $2.8 \mathrm{~cm}$ from the edge of the areola. The patient underwent ASM of the right breast and axillary lymph node dissection by a breast surgeon. The breast was immediately reconstructed with a TRAM flap, and the nipple was simultaneously reconstructed with a modified C-V flap. At 18 months postoperatively, the patient was satisfied with the outcome and had no recurrence, but a gutter-like depression around the reconstructed nipple occurred. The authors think this was probably due to excessive 


\section{Fig. 3. Preoperative and postoperative photographs of case 1}

(A) Preoperative view. (B) Eighteen-month postoperative view after immediate transverse rectus abdominis myocutaneous flap breast reconstruction and modified C-V flap nipple reconstruction following areola-sparing mastectomy of the right breast. There was a gutter-like depression around the reconstructed nipple (white arrow).
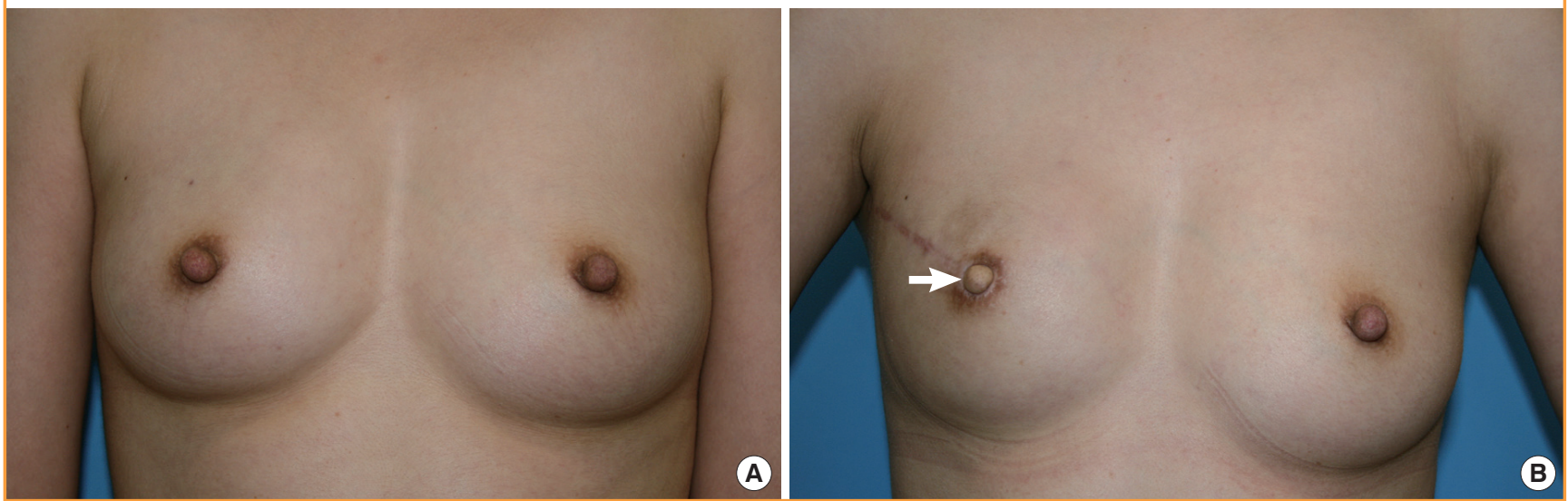

Fig. 4. Preoperative and postoperative photographs of case 2

(A) Preoperative view. The patient had already undergone conventional mastectomy of the left breast with immediate transverse rectus abdominis myocutaneous flap breast reconstruction. (B) Six-month postoperative view after immediate latissimus dorsi muscle flap breast reconstruction and modified C-V flap nipple reconstruction following areola-sparing mastectomy of the right breast.

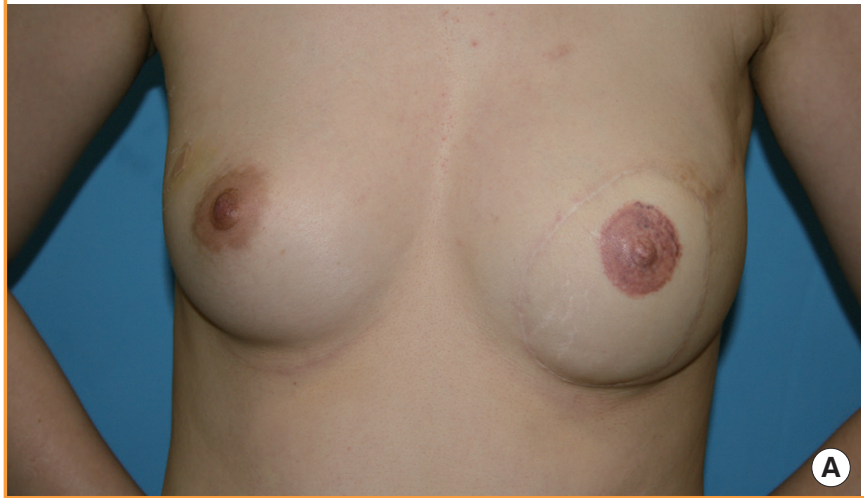

scarring around the nipple (Fig. 3).

\section{Case 2}

A 33-year-old female presented with invasive lobular carcinoma measuring $1.8 \mathrm{~cm} \times 1.5 \mathrm{~cm}$ in size in the right breast without nipple involvement. The tumor mass was $4.3 \mathrm{~cm}$ from the edge of the areola. She had already undergone conventional mastectomy of the left breast with immediate TRAM flap breast reconstruction 1 year earlier. The patient underwent ASM of the right breast and axillary lymph node dissection by a breast surgeon. The breast was immediately reconstructed with an LD flap and the nipple was simultaneously reconstructed with a modified $\mathrm{C}-\mathrm{V}$ flap. At 6 months postoperatively, the patient was satisfied with the outcome and had no recurrence (Fig. 4).

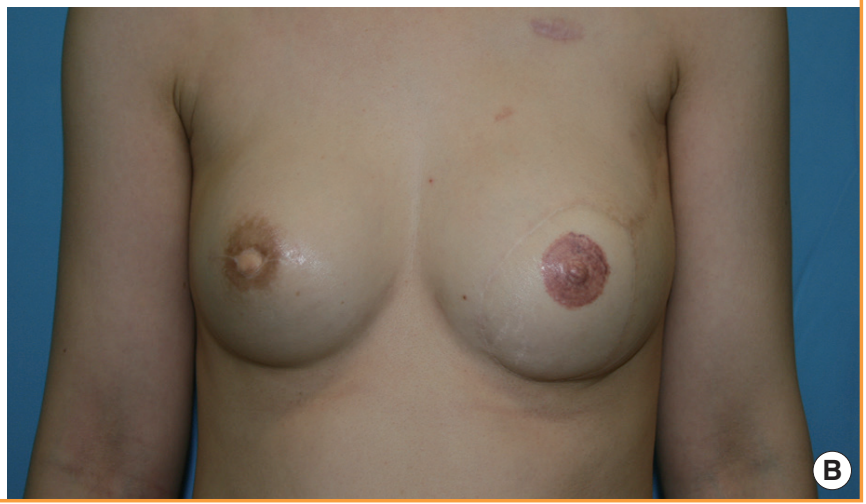

\section{DISCUSSION}

For over a decade, SSM has proven to be oncologically safe and has become the current standard of treatment for mastectomy with immediate breast reconstruction for early stage breast cancer $[2,3,12]$. Because a standard SSM technique includes resection of the nipple-areolar complex, patients need reconstruction of the nipple-areolar complex, which is usually performed as the final step in the reconstruction of the breast. However, the reconstructed areola is inferior to the natural areola because the areolar skin has a unique texture and color that is difficult to replicate by any areolar reconstruction technique. If the native areolar tissue can be preserved during mastectomy, a more natural appearing nipple-areolar complex could be achieved.

Recently, a new areolar preservation technique in SSM has emerged. This concept is based on anatomic differences between 
the areola and nipple [6]. The nipple is known to contain lactiferous ducts with accompanying smooth muscle complexes and copious sensory innervation. The areola contains sebaceous glands, sweat glands, and accessory areolar glands of Montgomery [13]. Simmons et al. [6] performed a pathologic analysis of 217 mastectomy specimens and found a less than $1 \%$ rate of malignant invasion of the areola. They concluded that removing the nipple along with the breast parenchyma and allowing preservation of the areola along with the skin does not increase the risk of future disease or possibility of occult disease being left behind. Recent studies have shown that in a carefully selected group of patients, ASM is an oncologically safe procedure [14]. If the tumor is located closer than $2 \mathrm{~cm}$ from the nipple or measures more than $4 \mathrm{~cm}$, there is a $>50 \%$ chance of nipple involvement $[15,16]$. Selection criteria for ASM include non-centrally located tumors smaller than $4 \mathrm{~cm}$ in size [14]. We also excluded patients with cancer masses larger than $4 \mathrm{~cm}$, invasive cancer, cancer involving the areola or nipple, inflammatory carcinoma, or locally advanced disease. Notably, in our series, there were no cases of cancer recurrence during the follow-up period. In addition to being oncologically safe, preservation of the native areola would confer a certain aesthetic advantage in breast reconstruction [17]. Furthermore, ASM performed in combination with immediate autologous breast reconstruction and nipple reconstruction represents a true single-stage reconstruction, with its inherent economic advantages and patient appeal [18].

Immediate nipple reconstruction following SSM without preservation of the areola has been described for both TRAM and LD flap reconstruction $[19,20]$. However, a single-stage reconstruction following ASM represents a new and innovative concept [21]. In our series, we found good to excellent results in all cases, and all of the patients were satisfied with the aesthetic results and the fact that they had to undergo surgery only once.

The possible complications of this technique include skin flap or areolar skin necrosis, irregular pigmentation or hypopigmentation of the areola, nipple-areolar complex malposition, hematoma, infection, and scarring. Since areolar skin necrosis can cause nipple distortion and an aesthetically undesirable areola due to scarring, it is recommended that the areola be sacrificed during the initial surgical procedure if the vascularity of the areolar skin is questionable [21]. The cases in which the areola was sacrificed were excluded from our study. Consequently, we did not experience necrosis of the skin flap or areola in any cases except for superficial skin erosion of the areola in one case.

Ma et al. [21] described the ability to avoid nipple tattooing in the final stage of reconstruction as an additional advantage of this technique. Because of the close proximity between the pigmented areola and nonpigmented nipple, melanocyte mi- gration is possible by means of chemokinesis and chemotaxis [22]. However, in our experience, all of the patients required additional tattooing due to irregular pigmentation or hypopigmentation. We suppose that the size of the nipple is too big for sufficient melanocyte migration, and the scar tissue between the areola and nipple interferes with melanocytic migration.

An additional problem with this technique is the gutter-like depression around the reconstructed nipple due to scarring along the border of the native areola and the new nipple, and the lack of a stable platform at the border. In order to solve this problem, we have devised some technical modifications that are under consideration, such as semicircular deepithelization of the areolar skin adjacent to the border to produce a stable platform [23] or using artificial dermis.

The major limitations of our study are the limited number of cases and short term follow-up. The average follow-up period (11 months) is less than the period required to conclude that no local recurrence has occurred. However, there does not appear to be any oncologic compromise in preserving the areolar skin, although larger, comparative studies with a longer follow-up are needed. From our experience, we suppose that one stage nipple and breast reconstruction following ASM is an oncologically safe, cost-effective, and aesthetically satisfactory procedure. Although Ma et al. [21] suggested this useful one-stage method of breast reconstruction, to our knowledge few clinical trials have been performed [24]. We also suggest that one-stage nipple and breast reconstruction following ASM is a good surgical option for breast reconstruction in carefully selected breast cancer patients.

\section{REFERENCES}

1. Rosenqvist S, Sandelin K, Wickman M. Patients' psychological and cosmetic experience after immediate breast reconstruction. Eur J Surg Oncol 1996;22:262-6.

2. Carlson GW, Bostwick J 3rd, Styblo TM, et al. Skin-sparing mastectomy: oncologic and reconstructive considerations. Ann Surg 1997;225:570-5.

3. Hidalgo DA. Aesthetic refinement in breast reconstruction: complete skin-sparing mastectomy with autogenous tissue transfer. Plast Reconstr Surg 1998;102:63-70.

4. Toth BA, Forley BG, Calabria R. Retrospective study of the skin-sparing mastectomy in breast reconstruction. Plast Reconstr Surg 1999; 104:77-84.

5. Mustonen P, Lepisto J, Papp A, et al. The surgical and oncological safety of immediate breast reconstruction. Eur J Surg Oncol 2004;30:817-23.

6. Simmons RM, Brennan M, Christos P, et al. Analysis of nip- 
ple/areolar involvement with mastectomy: can the areola be preserved? Ann Surg Oncol 2002;9:165-8.

7. Mathes SJ, Ueno CM. Reconstruction of the nipple-areola complex. In: Mathes SJ, Hentz VR, editors. Plastic surgery. 2nd ed. Philadelphia: Saunders Elsevier; 2006. p.791-818.

8. Mori H, Hata Y. Modified C-V flap in nipple reconstruction. J Plast Reconstr Aesthet Surg 2008;61:1109-10.

9. Salgarello M, Visconti G, Barone-Adesi L. Nipple-sparing mastectomy with immediate implant reconstruction: cosmetic outcomes and technical refinements. Plast Reconstr Surg 2010;126:1460-71.

10. McCarthy CM, Klassen AF, Cano SJ, et al. Patient satisfaction with postmastectomy breast reconstruction: a comparison of saline and silicone implants. Cancer 2010;116:5584-91.

11. Pusic AL, Klassen AF, Scott AM, et al. Development of a new patient-reported outcome measure for breast surgery: the BREAST-Q. Plast Reconstr Surg 2009;124:345-53.

12. Simmons RM, Adamovich TL. Skin-sparing mastectomy. Surg Clin North Am 2003;83:885-99.

13. Giacometti L, Montagna W. The nipple and the areola of the human female breast. Anat Rec 1962;144:191-7.

14. Simmons RM, Hollenbeck ST, Latrenta GS. Two-year followup of areola-sparing mastectomy with immediate reconstruction. Am J Surg 2004;188:403-6.

15. Kissin MW, Kark AE. Nipple preservation during mastectomy. Br J Surg 1987;74:58-61.

16. Cense HA, Rutgers EJ, Lopes Cardozo M, et al. Nipplesparing mastectomy in breast cancer: a viable option? Eur J
Surg Oncol 2001;27:521-6.

17. Simmons RM, Hollenbeck ST, Latrenta GS. Areola-sparing mastectomy with immediate breast reconstruction. Ann Plast Surg 2003;51:547-51.

18. Hammond DC. Prophylactic simple mastectomy and reconstruction, including prosthetic, latissimus, and transverse rectus abdominus myocutaneous flap techniques. In: Spear SL, Willey SC, Robb GL, et al., editors. Surgery of the breast: principles and art. Philadelphia: Lippincott Williams \& Wilkins; 2006. p.346-8.

19. Kim JT, Kim CY, Cha JH, et al. Immediate nipple reconstruction in breast reconstruction with TRAM free flap. J Korean Soc Plast Reconstr Surg 2005;32:76-84.

20. Delay E, Mojallal A, Vasseur C, et al. Immediate nipple reconstruction during immediate autologous latissimus breast reconstruction. Plast Reconstr Surg 2006;118:1303-12.

21. Ma G, Richardson H, Pacella SJ, et al. Single-stage breast reconstruction following areola-sparing mastectomy. Plast Reconstr Surg 2009; 123:1414-7.

22. Horikawa T, Norris DA, Yohn JJ, et al. Melanocyte mitogens induce both melanocyte chemokinesis and chemotaxis. J Invest Dermatol 1995;104:256-9.

23. Mohamed SA, Parodi PC. A modified technique for nippleareola complex reconstruction. Indian J Plast Surg 2011;44: 76-80.

24. Craig ES, Walker ME, Salomon J, et al. Immediate nipple reconstruction utilizing the DIEP flap in areola-sparing mastectomy. Microsurgery 2013;33:125-9. 